TEMPUS. Revista en Historia General Medellín (Colombia), 2018, septiembre-octubre, número 8

ISSN: 2422-2976

\title{
ESPAÑOLAS Y ESCLAVAS NEGRAS EN EL SIGLO XVI NOVOHISPANO
}

\author{
FEMALE SPANIARDS AND FEMALE BLACK SLAVES IN NEW SPAIN, XVI \\ CENTURY
}

Dra. María José Encontra y Vilalta ${ }^{1}$ Universidad Anáhuac México

\section{Resumen}

DOI: 10.17533/udea.tempus.n8a03

Este artículo nos acercará a una realidad novohispana poco tratada; se abordará la activa participación que tuvieron las mujeres peninsulares en la conformación de la sociedad virreinal y al mismo tiempo, la relación que mantuvieron estas mujeres con los esclavos de origen africano. Las fuentes utilizadas fundamentalmente para este trabajo son algunos de los documentos localizados en el Archivo de notarías de la Ciudad de México.

Palabras Clave: Esclavos africanos, mujeres peninsulares, documentos notariales.

\begin{abstract}
This article will bring us closer to a reality in the New Spain little treated; the active participation of the peninsular women in the formation of the viceroyal society and the same time, the relationship that these women with the slaves of African origin. The sources used mainly for this work, are located in the Archives of notaries of Mexico City.
\end{abstract}

Keywords: African slaves, peninsular women, notarial documents.

\section{Introducción}

Hablar de esclavitud es remontarnos a los albores de las culturas de Mesopotamia, en donde algunos seres humanos fueron considerados meramente objetos que se podían

\footnotetext{
${ }^{1}$ Doctora en Historia Universidad Iberoamericana ciudad de México; profesora e investigadora Universidad Anáhuac México. maria.encontra@anahuac.mx

${ }^{2}$ Sobre este punto se debe aclarar que, a pesar de ser comercializados, las leyes de cierta forma los protegían y se sancionaba a aquellos dueños que los maltrataban. En estos casos el esclavo podía denunciar a sus amos, aunque asumimos que esto no era muy frecuente.
} 
comprar, vender, intercambiar y también matar. ${ }^{2}$ La mayoría de ellos fueron esclavizados por medio de las actividades bélicas; aunque no deberían de pasarse por alto otras razones, como, por ejemplo, las deudas, que favorecían los intercambios de seres humanos. Menciones relacionadas con esta práctica a lo largo de la historia son numerosas, baste recordar el relato del Éxodo, en donde los protagonistas fueron esclavizados por los egipcios y liberados posteriormente por Moisés. A su vez, los pueblos de la Hélade y en concreto Aristóteles, justificaban el sistema apelando al derecho natural, a la superioridad que algunos pueblos desarrollados tenían sobre otros menos evolucionados. El Estagirita sostenía que los hombres no eran iguales, unos sabios y otros rústicos y, por lo tanto, los primeros debían de gobernar a los segundos; esto era la servidumbre natural. En estas culturas antiguas se asumía que los esclavos eran simplemente objetos, pero hablaban; por lo tanto, su comerció era lícito. Siglos más tarde, fue también una actividad muy importante y por lo mismo justificada por los romanos.

A partir de la Edad Media este sistema se sustentó ideológicamente por la doctrina aristotélica, el derecho cesáreo y las Partidas castellanas. ${ }^{3}$ En las Siete Partidas de Alfonso X El Sabio, la teoría del filósofo griego se redujo a tres tipos de esclavitud: las personas que habían sido capturadas en guerras y por ende enemigas de la fe, el ser hijo de una mujer esclava y, por último, venderse a sí mismo. A pesar de señalar esto, la sociedad peninsular durante el medioevo no fue esclavista en el sentido que pensamos de las sociedades antiguas, algunas familias, -encumbradas o artesanas- pudieron llegar a tener esclavos y la sociedad veía este tipo de relaciones como algo normal.

En la Baja Edad Media peninsular, a estos atenuantes alfonsinos, se les añadió uno más: el adoctrinamiento o la evangelización de las almas, y esto fue lo que precisamente argumentaron los portugueses. Durante el reinado de Enrique el Navegante, el tráfico se intensificó y el esclavo de origen africano se convirtió para algunos en un artículo indispensable. Los primeros portugueses que capturaron esclavos, estaban convencidos de que, al rescatarlos de sus respectivos pueblos, ga-

\footnotetext{
${ }^{3}$ José Andrés Gallego, La Iglesia y la esclavitud de los negros (Pamplona: EUNSA, 2002), 98.
} 
TEMPUS. Revista en Historia General Medellín (Colombia), 2018, septiembre-octubre, número 8

ISSN: 2422-2976

naban más almas para el cielo, y, tal fue así, que, el Papa Calixto III otorgó el 13 de marzo de 1456 la famosa Bula Inter Caetera en donde concedía a los portugueses el derecho a comerciar en esas tierras a cambio de la evangelización, este documento serviría de antecedente para la firma de Alcazobas unos años más tarde. Hasta finales del siglo XV muy pocos de los esclavos que circulaban en Europa eran originarios del África Subsahariana, la mayoría de ellos, habían sido capturados durante las múltiples guerras; es decir, los europeos de aquellos años convivían con esclavos, formando parte de sus realidades diarias.

Todo lo señalado cambió a mediados del siglo XV, cuando los portugueses con la intención de encontrar oro y nuevas rutas hacia las Indias, entraron en contacto con zonas occidentales del África subsahariana en donde los jefes locales intercambiaron hombres por baratijas europeas. De esta manera fue, como empezaron a introducirse en la Península Ibérica esclavos negros que se destinaron básicamente al trabajo doméstico y al comercio, "The firts africans slaves to be transported by the portuguese to the Iberian Peninsula were imported to the Algarve from Mauritania by the Lagos Company in 1444". ${ }^{4}$

A finales de la década de los setenta del siglo XV, Portugal se había convertido en el principal distribuidor de esclavos negros en la zona europea y, así lo reconocían los Reyes de Castilla y Aragón en los famosos tratados de Alcazobas de 1479. En poco tiempo y debido a su cercanía y ubicación estratégica, la ciudad de Sevilla se convirtió en el lugar más importante del comercio de esclavos negros en España y a partir de la empresa colombina, la capital del Guadalquivir se transformó en un lugar todavía más importante, pues su puerto conectaba el mercado europeo con las tierras americanas, enlazando así a los tres continentes. En la documentación notarial, que se presentará más adelante, se puede observar como hombres y mujeres de origen africano son mencionados junto con los objetos de labranza, con las mulas y los caballos, sin ningún tipo de preocupación por los involucrados en los contratos.

\footnotetext{
${ }^{4}$ Linda Newson, The Atlantic World, "From the capture to sale: The portugues slave trade to spanish south america in the early seventeenth century (Leiden, The Netherdlans: Brill, 2007), 3.
} 


\section{Los Tratados de Alcazobas y su repercusión en las Indias españolas}

Los Tratados de Alcazobas pusieron punto final a la guerra de sucesión castellana que enfrentó a los partidarios de Juana, apodada la Beltraneja y a Isabel de Trastámara. Después de varios años de guerras en la Península se firmó en la localidad portuguesa del mismo nombre, un tratado de paz en donde el rey Alfonso V de Portugal renunciaba a los derechos del trono castellano, y al mismo tiempo, Isabel y Fernando hacían lo mismo con los intereses portugueses. Todo esto ocurría en el año de 1479. Por esos mismos acuerdos, y entre otras cláusulas, a los portugueses se les reconocía el control de las costas occidentales de África, a excepción del archipiélago de las Canarias que quedaba bajo el dominio de los españoles.

El resultado y la importancia de estas resoluciones radica en que los portugueses tuvieron acceso y dominio a los principales enclaves costeros, lugares de donde se obtenían esclavos negros. Muy pronto, Sevilla se convirtió en el principal destino español de la mayoría de los subsaharianos y una vez consumada la empresa colombina, en un lugar de abastecimiento por excelencia, fundamentalmente durante los primeros años. Claro que este negocio, se fue transformando paulatinamente en función de los nuevos intereses, hasta consolidarse definitivamente a finales del siglo XVI; sobre todo, después de algunas de las aplicaciones que se hicieron de las Leyes Nuevas de 1542, como consecuencia a su vez, de las reducciones demográficas que sufrieron los naturales; ocasionando que la demanda de esclavos negros se incrementara considerablemente; continuando en cierto modo, con la trata mediterránea que se había dado a lo largo de la Edad Media.

A pesar de que las disposiciones reales prohibían y limitaban las actividades comerciales a los extranjeros, los intereses portugueses en la ciudad de Sevilla se fueron fortaleciendo a lo largo de los años. Ellos controlaban las principales fuentes de abastecimiento de esclavos, sobre todo, los de las regiones de Cabo Verde. La realidad fue, que la comunidad portuguesa y dentro de esta, los conversos, se afianzaron como los principales mercaderes y hombres de negocio de la región, vinculando sus economías a las redes financieras del norte de Europa y a lugares tan alejados como los virreinatos americanos. 
TEMPUS. Revista en Historia General Medellín (Colombia), 2018, septiembre-octubre, número 8 ISSN: 2422-2976

A tan sólo trece años de la firma de los Tratados de Alcazobas, Cristóbal Colón arribó a unas tierras que en principio pensó que se trataban de las Indias. Ese encuentro al que refiere Edmundo $\mathrm{O}^{\prime}$ Gorman $^{5}$ fue el acicate para que la trata de personas tomará un nuevo brío. La esclavitud ya existía, —ya se ha mencionado-, pero la forma en cómo se fue desarrollando a partir de esa fecha, no tuvo paralelo alguno. En América, el tráfico sufrió una fuerte transformación, pasando de la esclavitud al esclavismo. Los primeros esclavos que llegaron a las Antillas lo hicieron acompañando a sus amos, colaboraron en sus conquistas, en sus éxitos y en sus fracasos. Se sabe que Cristóbal Colón y otros de los que llegaron posteriormente a estas tierras lo hicieron acompañados por esclavos que les servían.

Desde finales del siglo XV cientos de personas africanas fueron extraídas por medio de engaños de sus respectivos lugares de origen por comerciantes portugueses que los permutaban por baratijas, para posteriormente venderlos en mercados internacionales, enlazando así tres continentes, Europa, África y América. Todo esto se intensificó cuando las poblaciones amerindias empezaron a reducirse debido al contagio de enfermedades como la viruela y el sarampión, afecciones que no causaban grandes estragos a los europeos ni a los africanos, pero sí a los naturales del continente americano.

\section{El acercamiento entre tres mundos: La Nueva España}

Ya se ha mencionado que la esclavitud como tal existía desde tiempos antiguos, incluso, en los territorios de la Península Ibérica no era un tema desconocido. Los primeros esclavos de origen africano empezaron a ser introducidos en forma regular a partir de los Tratados de Alcazobas. Se puede afirmar, que, desde ese momento hasta casi la entronización de Carlos I, prevaleció, —económicamente hablando-, el libre comercio. Este, se fue transformando paulatinamente, primero por el sistema de las licencias, hasta llegar en la última década del siglo a la práctica de los asientos. Inicialmente suponía el pago de dos ducados por cabeza, hasta que a principios de 1561 lo aumentaron a los treinta. Las licencias a su vez podían ser transferidas o traspasadas, con lo que el precio se incrementaba considerablemente.

${ }^{5}$ Cfr., Edmundo O'Gorman, La invención de América (México: FCE, 1995). 
Las primeras autorizaciones fueron otorgadas a los favoritos reales como pago o gratificaciones a servicios prestados. En estos contratos se indicaban las cantidades de esclavos que iban a ser trasladados a las respectivas zonas americanas. Este comercio se convirtió durante el siglo XVI en un rico filón y garantía de pago para la monarquía de los Habsburgo. Baste recordar a la familia Fucar, ellos ayudaron a financiar la entronización imperial de Carlos I y posteriormente solventaron las recurrentes deudas que tanto él como su hijo Felipe II fueron contrayendo.

Por otro lado, la llegada de los europeos a territorios antillanos supuso un cambio en las economías mundiales. A partir de la empresa colombina el orbe se hizo metafóricamente más pequeño; Europa y África, se interrelacionaron con los mercados americanos, tanto unos como los otros, fueron aprendiendo y adaptándose a las nuevas realidades y necesidades de abastecimiento de los centros económicos allende del mar. La primera referencia relacionada con esclavos negros de la zona antillana, procede de las instrucciones que se le entregaron a Nicolás de Ovando en septiembre de 1501, cuando:

Con mucho cuidado habemos de procurar la conversión de los indios a nuestra Santa Fe católica y si allí fueren personas sospechosas en la fe a dicha conversión, podrían dar algún impedimento, ni que allá vayan moros ni judíos, ni herejes ni reconciliados, ni personas nuevamente convertidas a nuestra fe, salvo si fueren esclavos negros u otros esclavos que hayan nacido en poder de cristianos. ${ }^{6}$

Esta cita confirma lo anteriormente mencionado, de que en la Península ya existía esclavitud y que era frecuente observar tanto a los esclavos blancos como a los subsaharianos en tareas domésticas y artesanales. Los primeros esclavos que llegaron a este continente provenían de los espacios peninsulares y lo hicieron acompañando a sus respectivos amos. Prácticamente, hasta el año de 1513 su llegada no fue controlada por parte de las autoridades, es decir, imperaba un libre comercio.

\footnotetext{
${ }^{6}$ Archivo General de Indias Sevilla, (AGIS), Indiferente General, 148. Leg. 1. fol.39 R-42R. Granada 16 de septiembre de 1501.
} 
TEMPUS. Revista en Historia General Medellín (Colombia), 2018, septiembre-octubre, número 8

ISSN: 2422-2976

La isla de Cuba se convirtió en muy poco tiempo en el centro de exploraciones americanas; desde la mayor de las Antillas, España promovía viajes de reconocimiento hacia nuevas tierras; aunque el entusiasmo inicial que supuso el periplo colombino pronto empezó a desilusionar a las autoridades y a los colonos, pues las islas no suponían el Dorado imaginado por los peninsulares. A esto se sumó un nuevo desencanto, los naturales pronto empezaron a sufrir la llegada de nuevas enfermedades y ante la imperativa necesidad de mano de obra, los comerciantes portugueses y sus filiales sevillanas aprovecharon la coyuntura para comerciar con sus productos provenientes de Cabo Verde, los esclavos.

La demanda de mano de obra esclava se incrementó de tal manera que el mercado peninsular por sí sólo no lo podía abastecer y percatándose Carlos I de los beneficios implicados, autorizó el 18 de agosto de 1518 en Zaragoza, la importación de 4000 esclavos guineanos, -sin la necesidad de pasar por territorio peninsular-, con la condición de que una vez llegados a las Antillas fueran cristianizados. Dentro del círculo cercano de Carlos I estaba el Gobernador de Bresa, Lorenzo de Gouvenot, a quién se le permitió su introducción. ${ }^{7}$ Dos meses después, exactamente el 21 de octubre y en la misma ciudad aragonesa, se le exentó del derecho del almojarifazgo. ${ }^{8}$ Estos privilegios fueron posteriormente vendidos por la cantidad 25000 ducados, encareciendo sucesivamente las ventas. Un año más tarde, Carlos I recibía la corona imperial por la muerte de su abuelo Maximiliano y paralelamente, Hernán Cortés salía de la isla de Cuba sin la capitulación correspondiente rumbo a tierra firme. En este viaje, el extremeño fue acompañado por varios esclavos negros y una vez consumada la Conquista en el año de 1521, el flujo de africanos empezó a incrementarse, pues se les requería en ingenios y minas.

Las políticas fueron cambiando y adaptándose a necesidades más concretas. Para tal efecto, Carlos I otorgó a cambio de 20,000 ducados, una licencia a Enrique Einger y a Jerónimo Seiler, -hombres de confianza de la familia Welser ${ }^{9}$-, para intro-

\footnotetext{
${ }^{7}$ AGIS, Indiferente General, 419, L.7, f.735 R-735V.

${ }^{8}$ AGIS, Indiferente General, 419, L.7, f.778R.

${ }^{9}$ Los Welser eran una familia de banqueros originarios de Ausburgo, Alemania, que junto con los Fuccar apoyaron la causa de entronización imperial de Carlos I.
} 
ducir durante cuatro años otros 4000 esclavos. La mayoría fueron destinados a los territorios actuales de Venezuela y Colombia en donde dicha familia tenía intereses económicos relacionados con la extracción de plata. ${ }^{10}$ Independientemente de las graciosas concesiones reales otorgadas a estos favoritos, los esclavos africanos siguieron llegando por otros medios a estas tierras, y la Nueva España no fue la excepción, puesto que en los registros de la Casa de Contratación aparecen con mucha frecuencia pasajeros que se trasladan a este virreinato acompañados de algunos esclavos africanos para su servicio personal, tal es el caso de Juan López, quien solicitó el 17 de enero de 1530 permiso para trasladarse a la Nueva España. Este hombre lo hizo con dos esclavos negros que estaban destinados a su servicio personal. ${ }^{11} \mathrm{O}$ el caso de Marina Estrada, quien dos años más tarde, el 12 de diciembre, solicitó de igual manera su traslado, y junto con ella, el de dos esclavos africanos para su servicio y atenciones personales. $^{12}$

Por casos como los anteriores y como consecuencia de las licencias individuales otorgadas, los alemanes protestaron enérgicamente a través de sus agentes Enrique Ynger y Jerónimo Sayler. ${ }^{13}$ En todos estos casos, los esclavos que llegaban al puerto de Veracruz debían de pagar sus correspondientes impuestos; es por esta misma razón que en muchas ocasiones se recurría al contrabando, pues con este método se lograba evadir el correspondiente pago de impuestos. El número de personas que atravesaron el charco durante el siglo XVI por este sistema nunca podrá ser comprobado.

\section{Españolas en el Virreinato novohispano}

En párrafos anteriores se ha mencionado que la sociedad peninsular estaba acostumbrada desde mediados del siglo XV a la presencia de esclavos africanos. Sobre todo, después de que los tratados de Alcazobas dieran a Portugal la oportunidad de

\footnotetext{
${ }^{10}$ AGIS, Diversas Colecciones, 45, N.11. Cédula real otorgada el 22 de abril de 1528, autorizando conquistar a Enrique Einger y a Jerónimo Sayler las zonas de Santa Marta hasta llegar a Marcapana.

${ }^{11}$ AGIS, Indiferente General 422, L.14, f.31 R (3).

${ }^{12}$ AGIS, Indiferente General 422, L.15, f.211, V-212 R.

${ }^{13}$ AGIS, Justicia 1169, N.4, R2. En este documento se aprecia como protestaron porque las autoridades otorgaban permisos o licencias de manera individual, reduciendo con ello los beneficios que podía suponer el control total y absoluto del comercio negrero.
} 
TEMPUS. Revista en Historia General Medellín (Colombia), 2018, septiembre-octubre, número 8

ISSN: 2422-2976

controlar los territorios costeros subsaharianos de donde obtenían esclavos negros. También se ha señalado, que éstos esclavos acompañaron a los primeros conquistadores y colonos que arribaron a los territorios antillanos. Es conveniente aclarar, que desde un principio las autoridades españolas pusieron un especial empeño en que los ideales peninsulares fueran traspasados a estos nuevos territorios. Una parte muy importante para conseguir lo mencionado era contar con la presencia de mujeres españolas, que, a partir de sus pautas culturales heredadas, transmitieran a estos territorios los valores mencionados. Dicho de otra forma, las mujeres formaron parte de la política imperial de conquista y colonización, y lo hicieron a través de la sangre.

A partir del segundo viaje colombino, familias enteras empezaron a llegar a los territorios del Caribe; la Corona, desde 1503 enfatizó la importancia de la migración femenina y para conseguir sus objetivos legislaron al respecto. No todas las mujeres que llegaron a estas tierras pertenecieron a los mismos niveles económicos ni sociales, pero todas ellas al unísono colaboraron en el mantenimiento, continuidad y control del orden social-familiar peninsular. Las fuentes revisadas indican, que las peninsulares fueron, además, una de las mayores aportaciones a la hora de consolidar los valores culturales europeos y, una vez instaladas en el Virreinato ejercieron de manera consuetudinaria lo vivido en la Península y colaboraron, además, en el arraigo de sus respectivos núcleos familiares. Entremezclaron los ideales medievales y renacentistas y de la misma manera aceptaron el modelo de la esclavitud que habían vivido en sus respectivos lugares de origen, es decir, no mostraban desagrado alguno ante el hecho de poseer esclavos originarios de África. La mayoría de estas peninsulares migraron a estos territorios obedeciendo a motivos familiares y algunas fueron acompañadas por esclavos negros que las atendían cotidianamente, no importaba el nivel económico. Se han localizado documentos de familias de artesanos, funcionarios y comerciantes que vinieron a la Nueva España en compañía de algún esclavo negro.

En general fue a partir de 1521 cuando los viajes empezaron a multiplicarse y, la población femenina se incrementó en forma constante. Las travesías hacia la Nueva España se iniciaban a finales de abril o principios de mayo y las cantidades de pasajeras que se trasladaron en esas naos o galeones fueron considerables, sobre todo a par- 
tir de la década de los años treinta, "Pues en cada viaje vienen muchas $"{ }^{14}$ El mejoramiento social para algunas, implicaba el hecho de que en la ciudad de Sevilla adquirieran antes de su salida algún esclavo que las acompañara, y una vez instaladas en el virreinato de la Nueva España representara un bien material que podían permutar o vender, generalmente, con cierto lucro.

\section{Españolas y esclavos africanos}

En la historiografía tradicional hasta hace muy poco tiempo se había asumido que las mujeres europeas habían tenido un mínimo papel en las gestas de conquista y colonización americana, pero esto no es cierto. La migración femenina hacia la Nueva España desde el inicio fue muy importante. Castellanas, andaluzas, o extremeñas, estuvieron insertas en todos los espacios sociales y económicos. ${ }^{15}$ Algunas tuvieron la fortuna de pertenecer a estamentos más privilegiados, otras no contaron con esa suerte, pero independientemente del nivel, los testimonios que dejaron fueron numerosos. Las leyes castellanas que se aplicaron en los territorios novohispanos muestran que las mujeres gozaron de casi los mismos derechos que los hombres,

Dentro de la sociedad en general - la mujer - tenía los mismos derechos que el hombre. Como el varón, adquiría la mayoría de edad a los veinticinco años, momento en el que ya podía, con pleno derecho y siempre que fuera soltera, realizar una amplia gama de transacciones legales, como, por ejemplo, disponer de bienes por compra, venta $\mathrm{u}$ otros medios, ajustar dotes, otorgar testamentos, etcétera. ${ }^{16}$

A partir de la documentación notarial que fue localizada en el Archivo de Notarias de la Ciudad de México, y en el Archivo de Indias de la ciudad de Sevilla, se encontraron mujeres de todos los estamentos sociales. En este apartado se mostrará la vinculación que tuvieron con los esclavos de origen africano. Los testimonios son numerosos y ricos en datos, que nos muestran que las españolas llegaron a estas tierras

\footnotetext{
${ }^{14}$ Enrique Otte, Cartas privadas de emigrantes a las Indias 1540-1616 (México: FCE, 1993), carta número 157, p.151. Diego de San Llorente a su mujer Luisa Sánchez.

${ }^{15}$ María José Encontra y Vilalta, "Mujeres Europeas en la capital de la Nueva España durante el siglo XVI" (Tesis de Doctorado, Universidad Iberoamericana, Ciudad de México, 2013).

${ }^{16}$ Ida Altman, Emigrantes y sociedad, Extremadura y América en el siglo XVI (Madrid: Alianza editorial, 1992), 181.
} 
TEMPUS. Revista en Historia General Medellín (Colombia), 2018, septiembre-octubre, número 8

ISSN: 2422-2976

desde antes de que fuera conquistada por Hernán Cortes en agosto de 1521. La información notarial es muy rigurosa, valga la expresión, y aunque sabemos, que no fue registrada para dejar testimonio de las actividades femeninas en la Nueva España, nos está acercando a una realidad, que hasta este momento ha sido desconocida o pasada por alto. En estos registros, encontramos datos de diversa índole: permisos para trasladarse a la Nueva España, contratos de compra y venta, traspasos, inventarios, y también, testamentos, liberaciones de esclavos, dotes o arras.

Prácticamente, en muchos de los registros mencionados se pueden apreciar mujeres peninsulares realizando o participando en diversas actividades. El primer documento de este tipo que se conserva de una mujer española, data del año 1525, y aunque no se menciona a ningún esclavo de color, si refleja actividad de una peninsular, llamada Francisca de Valdivieso, arrendando una huerta,

Juan Méndez, vecino de Tenustitlán, arrienda por un año a Francisca de Valdivieso, mujer de Juan Domínguez, vecino de Tenustitan,una huerta lindante con otra del Bachiller Alonso Pérez y otra de Hernán López de Ávila para que sea obligado de la labrar e poner ortalisa que a ella conviene, según uso y costumbre, fabricar una alberca y una puerta. $^{17}$

Será el 16 de noviembre de 1525, cuando aparece mencionada una mujer peninsular y una esclava africana.

Isabel de Ojeda, mujer de Antonio Villaroel, alguacil mayor, vecino de Tenustitlan, confiere poder a Juan Volante, vecino de la Villa Rica, para cobrar de Alonso Díaz, vecino de la misma villa, o de cualquier persona en cuyo poder estuviere, una esclava negra, que ha de nombre Catalina, con una criatura suya, la cual es mía y me pertenece. ${ }^{18}$

Las esclavas africanas también acompañaron a sus amas cuando estas decidieron trasladarse al nuevo mundo. Aunque siempre se prefería que viajaran familias completas, en ocasiones no podían hacerlo; entonces, los viajes los realizaban acom-

${ }^{17}$ Archivo de Notarias de la Ciudad de México, (ANCM), Francisca de Valdivieso, 13 de septiembre de 1525 , fols. $62 \mathrm{~V}$ y $63 \mathrm{R}$.

${ }^{18}$ ANCM, Isabel de Ojeda, 16 de noviembre de 1525, fols. $216 \mathrm{~V}$ y $217 \mathrm{~V}$. 
pañadas por algún familiar o esclavo. En este caso se puede mencionar nuevamente que las autoridades peninsulares estuvieron muy interesadas en que los valores culturales permearan en la Nueva España, es por ello, que se autorizó desde un inicio la llegada de mujeres relacionadas con cualquier tipo de profesiones, incluyendo las sanitarias. Algunas de ellas conocían de yerbas y además eran parteras. El primer registro que tenemos de una mujer con esta profesión lo ubicamos en el año de 1519, pero no hemos localizado que estuviera relacionada con una esclava negra. Será hasta 1566 cuando localicemos a una comadre originaria de Talavera de la Reina, ella viajó a la Nueva España con el permiso correspondiente. Por la documentación localizada en el Archivo de Indias en Sevilla, se sabe que Francisca Díaz, era viuda; pero este estado no le impidió realizar la larga travesía, al contrario, vino acompañada por un hijo, llamado Andrés Gutiérrez, que en ese momento contaba con unos quince años. Además, se sabe que el viaje lo realizó con una esclava negra que la ayudaba, es decir, era su asistenta. $^{19}$

\section{Contratos de compra-venta}

Los contratos de compra-venta generalmente se realizaban ante un escribano y/o notario, quien registraba y ratificaba el título de propiedad en un libro. Estos documentos son muy interesantes porque proporcionan una amplia cantidad de datos que pueden mostrar desde la procedencia del mismo esclavo, hasta sus características psicológicas, pasando por descripciones físicas, como podía ser, por ejemplo, la falta de un ojo. Estos contratos se realizaban, al igual que los demás, en presencia de testigos.

En los primeros registros, los datos consignados fueron muy austeros. De forma muy sencilla los escribanos dejaron testimonio de las diferentes operaciones y de los involucrados en las mismas, al inicio no se menciona el lugar de origen de los africanos registrados, pero, conforme fue avanzando la administración del Virreinato y con este sus procedimientos, los datos anotados en la documentación notarial serán más puntuales y variados. Es decir, en los primeros registros de notarías relacionados con esclavos africanos los datos consignados fueron muy austeros, esto obedecía, por

\footnotetext{
${ }^{19}$ AGIS, Francisca Díaz, Indiferente, 2051, N.32, fecha probable 1566.
} 
TEMPUS. Revista en Historia General Medellín (Colombia), 2018, septiembre-octubre, número 8

ISSN: 2422-2976

un lado, a que todavía no había descendido considerablemente la población de naturales, por lo tanto, la demanda era menor; y por el otro que los sistemas burocráticos apenas empezaban a estructurarse o burocratizarse, fue una etapa de aprendizaje,

Francisco Lombardo y Barbola de Saavedra, su mujer, vecinos de Tenustitlán-México, venden a Juan Pérez Sevillano, mercader, estante en la misma ciudad, 21 esclavos indios, hombres y mujeres herrados con el hyerro de Su Majestad, un esclavo y una esclava negros llamados Cristóbal y María, un caballo castaño, cojo, con un cherrión. ${ }^{20}$

Otro ejemplo que fue registrado el 22 de agosto de 1536, y ante el mismo escribano, Martín de Castro, de la cuarta escribanía, nos muestra un contrato de compra venta en donde María Gutiérrez, vende por 85 pesos de oro de minas, a Alonso Muñoz una esclava negra, el documento no da información adicional. ${ }^{21}$

María del Toral, viuda de Juan Beltrán, vecina, otorga carta de libertad a María, negra criolla, hija de Catalina de Zape, de 20 años. Color, negra criolla, alta de cuerpo, como dos veces de largo, el labio de abajo caído y es más grueso que el de arriba y los dos dientes delanteros y arriba anchos y no muy largos, que compró de almoneda pública que se hizo de los bienes de Francisca de Guzmán, viuda de Pedro de Brizuela, junto a otra esclava llamada Juana, su hermana. Y ello en atención a que recibió 500 pesos de oro común, en reales de plata que le dio por su rescate el Bachiller Pedro de Soto, clérigo, presbítero, recibiéndolos en dos pagos, unos de 290 pesos y el otro de 210. Testigos: Cristóbal Díaz del Toral, Alonso Díaz del Toral, Diego Gallego y Luis de Rueda, vecinos. ${ }^{22}$

Estos actos jurídicos pueden mostrarnos otro tipo de situaciones, es decir, se puede apreciar que, dentro de la compra o venta de un esclavo, pueden ir incluidos los hijos menores de edad, tal es el caso mencionado de la esclava Catalina, que Isabel de Ojeda en 1525 quiere recuperar. ${ }^{23}$ También, y esto ya se ha mencionado, los contratos,

\footnotetext{
${ }^{20}$ ANCM, Bartola de Saavedra, 19 de agosto 1536, fols.58 R y 59 R.

${ }^{21}$ ANCM, María Gutiérrez, 22 de agosto 1536, fols. 69 R y $69 \mathrm{~V}$.

${ }^{22}$ ANCM, María del Toral, 18 de marzo de 1593, Número de registro 797, Libro 1, foliación posterior $95 \mathrm{~V}$.

${ }^{23}$ ANCM, Isabel de Ojeda, 16 de noviembre de 1525 , fols. $216 \mathrm{~V}$ y $217 \mathrm{~V}$.
} 
sobre todo conforme va avanzando el siglo, muestran mayor información. Debe de registrarse cualquier tacha o descrédito del mismo bien vendido, de lo contrario el comprador podía demandar a la persona que vendió el esclavo. Tal es el caso de,

María de Espinosa, vecina, vende a Francisco de Baldenebro, vecino, una esclava negra llamada Juana, criolla de esta tierra, de edad de 22 años, habida en buena guerra y porque es ladrona, borracha, huidora, enferma y con todas las tachas y enfermedades públicas y secretas que pueda tener, por precio de 365 pesos de oro común, los cuales recibió en reales, de contado. No firmó. Testigos: Manuel de Silvera, Francisco de Torres y Pedro López, vecinos y estantes. ${ }^{24}$

Como se puede apreciar, cada vez fueron más los datos incorporados en los documentos. Se puede decir, que la esclava Juana había nacido en estas tierras americanas, tenía problemas de alcoholismo y además era cleptómana, pero había sido obtenida en buena guerra, siempre debían de serlo. El no mencionar estos defectos o imperfecciones, el vendedor podía hacerse cargo de una sanción, o, reclamación que podía realizarle posteriormente el comprador al darse cuenta.

La esclavitud para que no causará conflictos en la conciencia y para que pudiera ser lícita, debía de realizarse solamente con prisioneros de guerra, de lo contrario, implicaba un serio problema de honestidad, y, por lo tanto, se consideraba ilegal. Este punto, es un poco delicado; se asume, que a pesar de que en todos los contratos aparece la leyenda de la guerra justa, ¿quién podía finalmente asegurarlo?, a los negreros poco les importaba la manera, siempre y cuando hubiera compradores que adquirieran su mercancía y a su vez, los compradores, se daban por bien servidos simplemente con la mención de guerra justa, más no con la comprobación de la misma.

\section{Poderes y dotes}

Los poderes fueron otro de los tipos de documentación apreciada durante el siglo XVI, y que guardó relación con la población peninsular femenina. En estos documentos, las mujeres dueñas de esclavos, delegaron a una tercera persona cierta mi-

\footnotetext{
${ }^{24}$ ANCM, María de Espinosa, 19 de julio de 1578, Número de registro, 2025, foliación original $312 / 312 \mathrm{~V}$.
} 
TEMPUS. Revista en Historia General Medellín (Colombia), 2018, septiembre-octubre, número 8

ISSN: 2422-2976

sión, como pudo ser la recuperación de la esclava Catalina, o el caso de Bernardina Torres, viuda de Luís de Godoy, quien se presentó ante el notario Antonio Alonso el día primero de diciembre del año de 1572, para otorgar un poder a Luis Rueda, vecino de la ciudad de México, para que cobrara ciertas deudas y objetos, dentro de esto testimonio notarial, mencionaba a esclavos; estos siempre aparecen descritos junto con instrumentos de trabajo y otras propiedades. ${ }^{25}$

Por otro lado, las dotes permitieron conservar y afianzar a las familias más importantes de la Nueva España; generalmente, estos convenios fueron el resultado de previas y largas negociaciones que involucraba a las dos familias. Este tipo de alianzas se incrementaron conforme se iba consolidando el grupo peninsular en estas tierras, y fue una de las prácticas que fortalecieron a la oligarquía novohispana, grupos de conquistadores se emparentaron entre sí con la finalidad de robustecer su poder económico y social. Aunque parezca paradójico, este tipo de contratos fueron más abundantes durante los primeros años del virreinato. Sirvieron también, para fortalecer y beneficiar a familias de artesanos, que, aunque no pudientes, sí unían y hacían más grande el beneficio familiar.

Las dotes eran, la entrega de bienes que hacía la familia de la mujer al futuro marido. Era una costumbre que se venía aplicando en algunos grupos peninsulares y que se transmitió como ocurrió con muchas otras situaciones a los territorios americanos. Esta antigua práctica peninsular se remontaba al derecho romano y al visigodo. También, en el caso de la Nueva España, debe de buscarse su origen en las Partidas, "es algo que da la mujer al marido por razón de casamiento es llamado dote, et es la manera de donación fecha con entendimiento de se mantener et ayudar el matrimonio con ella. Et según dicen los sabios antiguos es como el propio patrimonio de la mujer". ${ }^{26}$

${ }^{25}$ ANCM, Bernardina Torres, 1 de diciembre de 1572, Volumen 9, legajo, 18, fols. 209/210.

${ }^{26}$ Las Siete Partidas del Rey Don Alfonso X el Sabio, cotejadas con varios códices antiguos por la Real Academia de Historia (Madrid: Imprenta Real, 1807), tomo III, partida IV, Título XI, Ley I, 63. 
La dote permitió conservar dentro de los más altos estamentos sociales los capitales familiares; aunque también se observan dotes más modestas correspondientes a los sectores artesanos. En estos documentos se incluyen muebles, ropa, y otros objetos, entre ellos a los esclavos, pues al fin y al cabo eran objetos que se intercambiaban y vendían. El 16 de junio de 1566, se registró un compromiso de dote por parte de Alonso de Cárdenas y de su esposa Luisa de Páez, ante el notario Antonio Alonso. Su hija Magdalena iba a aportar al matrimonio una considerable cantidad para la época, que ascendió a 4129 pesos de oro común, además de algunos bienes raíces y "una esclava negra, nombrada Elena, de tierra de Jalofe, de edad de 30 años, tasada en 350 pesos. Un esclavo negro Antón, de tierra de Zape, de 17 años, entre bozal y ladino, por 350 pesos.${ }^{27}$ Estos bienes eran siempre propiedad de la esposa y el marido solamente fungía como usufructuario, en algunos casos las dotes y su contraparte las arras, ocasionaron conflictos entre ambas partes, sobre todo cuando los herederos inconformes alegaban ciertos derechos de las mismas.

\section{Deudas}

Otro tipo de documento relacionado con la esclavitud es la deuda, que en términos generales consistía en cantidades de dinero que faltaban por completar normalmente tenía que concluirla el comprador-, cuando realizaba alguna transacción económica; ya fueran estas, bienes raíces, préstamos de dinero o compra-venta de esclavos. Las deudas o los compromisos no cubiertos podían llevar al encarcelamiento. Se podían concertar con comerciantes establecidos en la Nueva España, con mercaderes asentados en la ciudad de Sevilla, o con personas particulares.

Se han localizado varios documentos de este tipo, uno de los más antiguos lo registró Juan Hernández del Castillo, su labor como notario duró muy poco tiempo, prácticamente un año, del 27 de diciembre de 1527 al 1 de diciembre de 1528. Durante estos meses y como parte de su gestión, se le presentó el matrimonio compuesto por

\footnotetext{
${ }^{27}$ ANCM, Luisa Paz y Magdalena Paz, 16 de junio de 1566, 741, fols. 90/3. Los esclavos provenientes de la tierra de Zape no eran muy valiosos, pues tenían fama de huidizos, borrachos y ladrones. La esclava Elena, era Jalofe, en su momento las personas procedentes de esa zona, tenían fama de salvajes y antisociales; aun así, fueron vendidos.
} 
TEMPUS. Revista en Historia General Medellín (Colombia), 2018, septiembre-octubre, número 8

ISSN: 2422-2976

Alonso García Albani y Ana Pérez, quienes reconocieron deber a un mercader sevillano la cantidad de 48,000 maravedís. Entre los varios conceptos mencionados, estaba un esclavo negro, llamado Antón. ${ }^{28}$ Esta referencia no aporta mayor información, debido a que fue realizada poco tiempo después de haberse conquistado la ciudad de México y, por lo tanto, todavía no estaba bien definida lo que posteriormente será la burocracia novohispana en el sentido amplio de la palabra. Desconocemos, por lo tanto, el lugar de origen y la procedencia del mismo Antón.

\section{Testamentos y alhorrías}

Los testamentos localizados nos presentan una gran cantidad de datos, sobre todo cuando va avanzando el siglo. Son testimonios patrimoniales que realizaron las mujeres peninsulares poco tiempo antes de su fallecimiento, $\mathrm{y}$, como todos los bienes quedaban registrados, los esclavos, -bienes-, también quedaron anotados. Generalmente cuando se abrían los testamentos lo que procedía posteriormente era cumplir cabalmente con lo estipulado, para ello en muchas ocasiones se recurría a las almonedas públicas, que eran licitaciones previamente anunciadas, en donde se remataban los bienes, en este caso, los mismos esclavos. Los testamentos, al mismo tiempo, nos proporcionan datos que en líneas generales nos permiten visualizar las relaciones que mantuvieron los amos con sus esclavos, posiblemente se crearon lazos de afecto y agradecimiento.

Es el caso de Francisca Guzmán, quien en 1587 otorgó una carta de libertad a su esclava Catalina; este documento es muy interesante, porque entre otras cosas menciona su origen: de la tierra de Zape. También se sabe que su libertad estuvo condicionada durante cuatro años, al término de los cuales finalmente sería libre. El testimonio también menciona, que ésta tenía dos hijas, las cuales, igualmente, formaban parte de los bienes de Francisca Guzmán. Otra parte del documento nos menciona que la esclava Catalina estaba marcada en el rostro.

Cristóbal Díaz del Toral, vecino y albacea testamentario de Francisca Guzmán, viuda de Pedro de Brizuela, difunta, vecina que fue de México por testamento

${ }^{28}$ ANCM, Ana Pérez de Aviñón, 9 de junio de 1528, III, fols. 396 V y 397 R. 
otorga carta de libertad a Catalina, esclava negra de 40 años, que tiene en el rostro un letrero que dice "maestro de Roa" de quien fue anteriormente esclava, de la tierra de Zape. Con declaración de que se cumplió con la cláusula testamentaria que estipulaba, que, al fallecimiento de Francisca Guzmán, la esclava quedaría en servicio de Doña Isabel de Luján, a quien debía de pagar 4 reales de plata cada semana, durante cuatro años, antes de conseguir la libertad. Y con la aclaración de que las hijas de Catalina, Mariana y Juana, siguieron como parte de los bienes de Francisca Guzmán, quien nombró en su testamento a Cristóbal Díaz del Toral, a Doña Isabel de Luján y a Fray Francisco Jiménez de la orden de Santiago de la Ciudad de México, como sus albaceas, siendo testigos de dicho testamento Juan de Cedilla, Martín de Guecho y Fray Juan de Sena, estantes en México. Testigos de esta escritura: Luis Palacio el mozo, Juan Rodríguez y Luis Coronado, vecinos. ${ }^{29}$

En estos documentos, que ya se ha dicho, se encuentra filón documental que tardará en mostrar su gran riqueza, debido a la gran abundancia de escritos. Un ejemplo de los muchos localizados nos lo dejó el escribano Luis de Basurto, cuando mencionó al esclavo Juan Francisco de 24 años, criollo comprado en Cádiz, y que Doña Isabel de Hinojosa vendió en almoneda pública por 400 pesos de oro común. En este escrito, además, se aprecia que lo compraron dos personas, es decir, una especie de sociedad. A pesar de registrarse este dato, el documento no menciona como iba a dividirse el tiempo, o en qué tareas lo iban a destinar,

Doña Isabel de Hinojosa, viuda de Jerónimo Cataño Bohórquez, vecina, como tutora y albacea de los bienes de sus hijos, vende en almoneda pública, al canónigo Hurtado Ortiz de Hinojosa y también albacea, su hermano y a Bernardino de Estrada, vecino, un esclavo criollo de Cádiz, de Castilla, llamado Juan Francisco de 24 años, alto de cuerpo, sacado a la Plaza Mayor en el portal de los Mercaderes, por voz de Pedro de Aguilar, pregonero público, por precio de 400 pesos de oro común. Testigos: Iñigo de Carrizosa, Andrés Dávila y Luis Santos, vecinos. ${ }^{30}$

${ }^{29}$ ANCM, Francisca Guzmán, Alhorría, 21 de enero de 1594, Número de registro 791, Libro 1, fols. $89 / 90 \mathrm{~V}$.

${ }^{30}$ ANCM, Isabel de Hinojosa, Almoneda, 1 de abril de 1593, Número de registro 803, Libro 1, fol. $100 \mathrm{~V}$. 
TEMPUS. Revista en Historia General Medellín (Colombia), 2018, septiembre-octubre, número 8 ISSN: 2422-2976

\section{Conclusiones}

A lo largo de estas líneas y aunque de manera breve, se ha tratado de demostrar la relación de las españolas y las esclavas de origen africano en la ciudad de México durante el siglo XVI. La documentación que se ha presentado es solamente la punta de un gran iceberg, presenta una gran riqueza que deberá de aflorar en futuras investigaciones. Nos ha mostrado diferentes facetas sociales y económicas, en donde ambos colectivos estuvieron enlazados en unos años que fueron de gran importancia para el desarrollo del virreinato de la Nueva España, y cuya influencia todavía es patente en el México actual. Al mismo tiempo se ha podido demostrar a través de los documentos revisados, que las mujeres peninsulares desde un principio aparecieron en las gestas americanas relacionándose con tanto con los esclavos provenientes del áfrica Subsahariana como con los nacidos ya en estas tierras, es decir, los llamados criollos.

\section{Bibliografía}

AGUIRRE, Gonzalo. La población negra de México. México: FCE, 1972.

ALTMAN, Ida. Emigrantes y sociedad, Extremadura y América en el siglo XVI. Madrid: Alianza editorial,1992.

ENCONTRA, María José. Mujeres europeas en la capital de la Nueva España durante el siglo XVI. Tesis Doctoral, Universidad Iberoamericana. México: 2013.

GALLEGO, José Andrés. La Iglesia y la esclavitud de los negros. Pamplona: EUNSA, 2002.

KLEIN, Herbert. African slavery in Latin America and the Caribbean. Oxford: University Press, 2007.

MIRA, Esteban. "Las licencias de esclavos negros a Hispanoamérica, 1554-1550". Revista de Indias Tomo LIV, número 200 (1994).

NAVARRETE, María Cristina. Génesis y Desarrollo de la esclavitud en Colombia, siglos XVI y XVII. Cali, Colombia: Programa editorial, Universidad del Valle, 2005. 
Dra. María José Encontra y Vilalta

NEWSON, Linda and Susie Minchin. From the capture to sale: The portugues slave trade to spanish south america in the early seventeenth century. Leiden, The Netherlands: Brill, 2007.

O'GORMAN, Edmundo. La invención de América. México: FCE, 1995.

OTTE, Enrique. Cartas privadas de emigrantes a las Indias 1540-1616. México: FCE,1993.

\section{Archivo General de Indias, Sevilla}

AGIS, Indiferente General, 148. L. 1. Fol.39 R-42R.

AGIS, Indiferente General, 419, L.7, F.735 R-735V.

AGIS, Indiferente General, 419, L.7, F.778R.

AGIS, Diversas Colecciones, 45, N.11.

AGIS, Indiferente General 422, L.14, F.31 R (3).

AGIS, Indiferente General 422, L.15, F.211, V-212 R.

AGIS, Indiferente, 2051, N.32, fecha probable 1566.

AGIS, Justicia 1169, N.4, R2.

\section{Archivo de Notarias de la Ciudad de México.}

ANCM, Francisca de Valdivieso, 13 de septiembre de 1525, fols. 62 V y 63 R.

ANCM, Isabel de Ojeda, 16 de noviembre de 1525, fols. 216 V y 217 V

ANCM, Bartola de Saavedra, 19 de agosto 1536, fols.58 R y 59 R.

ANCM, María Gutiérrez, 22 de agosto 1536, fols. 69 R y 69 V.

ANCM, María del Toral, 18 de marzo de 1593, Número de registro 797, Libro 1, foliación posterior $95 \mathrm{~V}$. 
TEMPUS. Revista en Historia General Medellín (Colombia), 2018, septiembre-octubre, número 8 ISSN: 2422-2976

ANCM, Isabel de Ojeda, 16 de noviembre de 1525, fols. $216 \mathrm{~V}$ y $217 \mathrm{~V}$.

ANCM, María de Espinosa, 19 de julio de 1578, Número de registro, 2025, foliación original $312 / 312 \mathrm{~V}$.

ANCM, Bernardina Torres, 1 de diciembre de 1572, Volumen 9, legajo, 18, fols. $209 / 210$

ANCM, Luisa Paz y Magdalena Paz, 16 de junio de 1566, 741, fols. 90.

ANCM, Ana Pérez de Aviñón, 9 de junio de 1528, III, fols. 396 V y 397 R

ANCM, Francisca Guzmán, Alhorría, 21 de enero de 1594, Número de registro 791, Libro 1, fols. 89/90V.

ANCM, Isabel de Hinojosa, Almoneda, 1 de abril de 1593, Número de registro 803, Libro 1, fol. $100 \mathrm{~V}$. 